\title{
RAZVOJ LIDERSTVA I DETERMINISANJE MODERNOG PRISTUPA LIDERSTVU
}

\section{LEADERSHIP DEVELOPMENT AND DETERMINATION OF MODERN APPROACH TO LEADERSHIP}

\author{
Vuk Mirčetić \\ Institut za pravo i finansije, Beograd, Srbija
}

CMESTE

JEL Kategorija rada: 015

\begin{abstract}
Apstrakt
Multidimenzioni proces liderstva nije tekovina savremenog doba, već se javlja vekovima unazad, dok ga istraživači analiziraju od početka dvadesetog veka. Promene kontekstualnih faktora oduvek primoravaju organizacije da ih prepoznaju i da im se prilagode ili da se sa istima izbore. Svaka organizacija ima potrebu za efektivnim liderima jer na taj način mogu da iskoriste maksimalni trud svojih zaposlenih i tako pospeše poslovanje. Mnogi teoretičari su pokušali da shvate, definišu i objedine odnos u kojem pojedinac vrši uticaj na grupu pojedinaca radi postizanja određenog cilja. Iz tog razloga su nastali brojni teorijski pristupi kompleksnosti liderskog procesa. U dvadesetom i dvadesetprvom veku nastalo je nekoliko stotina definicija liderstva, a ni danas se istraživači i praktičari ne slažu oko postojanja univerzalne definicije liderstva. Kroz decenije istraživačkog rada pristup liderstvu se menjao i evoluirao. $U$ radu su kroz raznovrstan teorijski pregled analizirani različiti pristupi liderstvu $i$ sprovedena komparacija teorija liderstva. Cilj rada je da omogući uvid u evoluciju liderstva, prikaže savremene teorije liderstva i determiniše moderni pristup liderstvu.
\end{abstract}

Ključne reči: liderstvo, liderski proces, teorije, moderni pristup liderstvu, menadžment ljudskih resursa

\begin{abstract}
The multidimensional leadership process did not arise in the modern era, it occurs for centuries, while researchers have analyzed it since the early twentieth century. Contextual factors change and that always forces organizations to recognize them and to adapt to them or to cope with them. Every organization has the need for effective leaders because in this way they can take advantage of the maximum effort of their employees and thus speed up their business. Many theorists have tried to understand, define and unify the relationship in which an individual exercise influence on a group of individuals in order to achieve a certain goal. For this reason, numerous theoretical approaches to the complexity of the leadership process have arisen. In the twentieth and twenty-first centuries, several hundred definitions of leadership were created, and today researchers and practitioners do not agree

Adresa autora:

Vuk Mirčetić

䒠泣vuk.mircetic@ipf.rs

on the existence of a universal definition of leadership. Through decades of research, the approach to leadership is changing and evolving. Different theories and approaches
\end{abstract}


to leadership have been analyzed through a diverse theoretical overview and comparison. The aim of the paper is to provide an insight into the evolution of leadership, to present an overview of contemporary leadership theories and to determine a modern approach to leadership.

Keywords: leadership, leadership process, theories, modern leadership approach, human resource management

\section{UVOD}

Svakodnevne promene u kojima kontekstualni faktori imaju važnu ulogu stvaraju neophodnost postojanja efektivnog liderstva. Pojedini autori su izdvojili šest kontekstualnih faktora među kojima su demografija, tehnologija, društveni običaji, državne intervencije, rad i globalni događaji i posmatrali uticaj promena tih faktora (Mayo \& Nohria, 2005). Efektivni lideri treba da kontekstualne faktore prvo prepoznaju, a zatim i na adekvatan način savladaju, jer oni direktno utiču i na promene u društvu, zajednicama, organizacijama, ali i među pojedincima u grupi. Promene se dešavaju neprestano, a pristupi liderstvu se razvijaju uz njih kako bi se na što bolji i efektivniji način suočili sa promenama i problemima. Mnogi istraživači su istraživali fenomen liderstva u cilju dobijanja saznanja ko su to lideri, kako se lider postaje i šta predstavlja efektivno liderstvo i u više od veka istraživanja ovog fenomena, liderstvo nije determinisano.

Poput nepostojanja jedinstvene definicije liderstva, ne postoji ni jedinstven šablon koji određuje da li će jedan lider biti uspešan ili ne. Najbolji lideri imaju i pokazuju različite osobine, stavove, vrednosti i snage (Drucker, 2017), tako da je nemoguće odrediti jedan pristup liderstvu koji će pojedinca odrediti kao efektivnog lidera ili ne.

Konstantnim i brzim promenama prilagođava se i pristup liderstvu. U cilju razumevanja modernog pristupa liderstvu neophodno je sagledati uporedno teorijski prikaz razvoja liderstva. Liderstvo postoji znatno duže nego što ga istraživači izučavaju kao pojam. Od imperatora i konzula u doba starog Rima i modela ko-liderstva (Sally, 2002) preko pristupa liderstvu koje odlikuje iskazivanje moći lidera u odnosu na sledbenike do novog pristupa koji stavlja grupu u fokus. Novi koncept naziva se dinamika grupe i u fokusu ima članove grupe. Napori u okviru istraživanja naučnika podvukli su značaj učešća zaposlenih u donošenju odluka. Dokazi do kojih se došlo otvorili su pitanja izraženog direktivnog liderstva i pokazali da postoji potreba obraćanjem više pažnje na probleme motivacije i međuljudskih odnosa (Tannenbaum \& Schmidt, 1973).

\section{DEFINISANJE LIDERSTVA}

Definicija liderstva ima skoro onoliko koliko i autora koji su pokušali liderstvo da definišu (Stogdill, 1974). Uporednom analizom studija na temu liderstva dolazi se do zaključka da postoje različiti teorijski pristupi liderstvu (Day \& Antonakis, 2012; Bryman, Collinson, Grint, Jackson, Uhl-Bien, 2011; Hickman, 2009; Mumford, 2006; Bryman, 1992; Rost, 1991; Bass, 1990; Gardner, 1990). Rezultati uporedne analize govore da su autori različitih teorija i pristupa liderstvu saglasni da je liderstvo kompleksni multidimenzioni proces i kao takav će i biti analiziran u ovom radu.

Pojedini autori (Northouse, 2016; Shackleton, 1995) smatraju da liderstvo karakterišu četiri komponente:

1. Proces;

2. Uticaj;

3. Grupa;

4. Cilj.

Od izuzetne važnosti je da sve četiri komponente moraju da postoje. Liderstvo je proces koji traje i čini međusobni odnos između pojedinca i grupe pojedinaca koji se u teoriji nazivaju lider i sledbenici. Liderima su potrebni sledbenici i sledbenicima su potrebni lideri (Hollander, 1992; Heller \& Van Til, 1983; Jago, 1982; Burns, 1978), a samo liderstvo bez lidera ili sledbenika ne postoji. lako su usko povezani, lider je najčešće onaj koji pokreće i održava odnos između lidera i sledbenika (Northouse, 2016). Njihova interakcija je od izuzetne važnosti u cilju ostvarivanja uticaja lidera na sledbenike, ali i kako bi grupa zajedno mogla da ostvari neki uticaj radi ostvarivanja određenog zadatka. Cilj koji grupa ima treba da bude zajednički ili da ga grupa percipira kao takav. Lider može i grupu da dovede u zabludu da je neki cilj zajednički, te da sledbenici rade na ostvarivanju određenog cilja za koji pogrešno 
smatraju da je i njima u interesu. Ponekad se uloga lidera posmatra elitistički s obzirom da sa sobom nosi moć (Burns, 1978), ali se mora imati $u$ vidu da lideri nisu niti iznad svojih sledbenika niti su nužno bolji od njih. Lideri i sledbenici treba da se posmatraju i razumeju kroz međusobni odnos (Hollander, 1992) i zajedno (Rost, 1991; Burns, 1978).

Premda već više od jednog veka brojni autori pokušavaju da odrede liderstvo, saglasnost nije postignuta i ne postoji sublimirana $i$ jedinstvena definicija liderstva. Ukoliko uključimo četiri pomenute ključne komponente, liderstvo se može determinisati na sledeći način:

Liderstvo je proces koji predstavlja međusobni odnos lidera i sledbenika u kom lider utiče na grupu da preduzme određene aktivnosti radi ostvarivanja zajedničkog cilja.

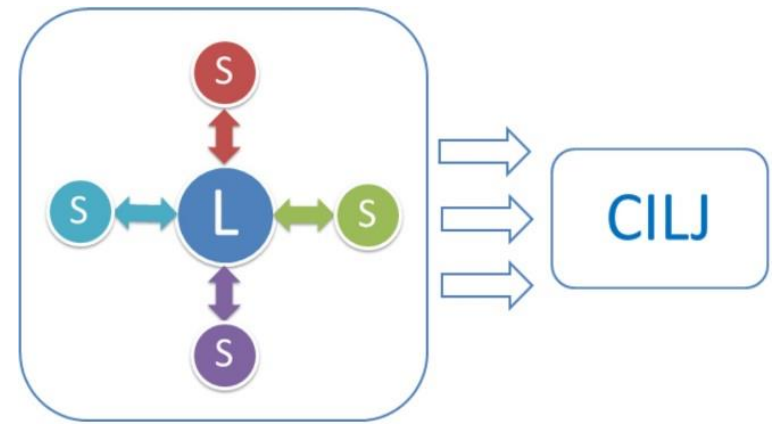

Slika 1. Grafički prikaz definisanja liderstva

Definicija liderstva postavljena na ovaj način ostavlja otvorene razne mogućnosti i stoga je pogodna da u svoj okvir obuhvata i različite teorije i pristupe.

\section{RAZVOJ LIDERSTVA TOKOM DVADESETOG VEKA}

$\mathrm{U}$ poslednjih više od sto godina izučavaju se različiti teorijski pristupi kompleksnosti liderskog procesa. Rost (1991) je analizirao definicije liderstva u periodu od 1900. do 1990. godine i izdvojio preko dve stotine različitih definicija liderstva, što je pružilo uvid u to na koji način je liderstvo bilo definisano $u$ kom periodu, kao i način razvoja liderstva tokom vremena.

Početkom dvadesetog veka liderstvo je povezivano sa dominacijom, tačnije kontrolom $\mathrm{i}$ centralizacijom moći. Liderstvo je smatrano sposobnošću da se prenese volja lidera na sledbenike i podstakne poslušnost, poštovanje, lojalnost i kooperacija (Moore, 1927). Liderstvo nije određeno demonstriranjem moći, već mogućnošću da se poveća osećaj postojanja moći lidera kod sledbenika (Follet, 1924).

Narednih godina, pojam liderstva se razdvajao od povezivanja sa prinudom (Copeland, 1942) i počinjalo je da se objašnjava kao ponašanje pojedinca koji je uključen u upravljanje aktivnostima određene grupe. (Hemphill, 1949).

Pedesetih godina dvadesetog veka nastavilo se sa teorijama liderstva koje su obuhvatale međusobne odnose i šta to lider radi u grupi, usmereno najviše na samo ponašanje lidera $i$ odnos sa sledbenicima koji razvija i postiže zajedničke ciljeve. Istraživači su u ovom periodu počeli da govore i o efektivnosti u domenu liderstva u kojem je liderstvo bilo definisano kao sposobnost da se utiče na ukupnu efektivnost grupe (Northouse, 2016). U periodu koji sledi, autori su proširili postojeće definicije opisivanjem liderstva kao činjenja od strane pojedinca koja utiču na druge pojedince da se pokrenu $u$ zajedničkom pravcu. Autori su sedamdesetih godina kao polazište uzeli fokus na grupu $i$ proširili, tako da je liderstvo definisano kao reciprocitetni proces mobilisanja od strane pojedinaca sa određenim motivima i vrednostima, različitih ekonomskih, političkih i drugih resursa, u kontekstu nadmetanja i konflikta, u cilju da se ostvare ciljevi koje lideri i sledbenici imaju pojedinačno ili zajedno (Burns, 1978). Analiziranjem definicija liderstva ovog perioda, za liderstvo se može reći da predstavlja iniciranje ili održavanje grupe ili organizacije da postigne ciljeve grupe ili organizacije (Rost, 1991).

Jedan od najplodonosnijih perioda kada je $u$ pitanju teorija o liderstvu su osamdesete godine prošlog veka kada su istraživači ponudili veliki broj različitih teorijskih pristupa kompleksnosti liderskog procesa koje se mogu obuhvatiti u nekoliko grupa sa sličnim temama:

- Uloga liderstva je da sledbenici urade onako kako lider želi;

- Liderstvo se definisalo kao vršenje uticaja na način koji nije prisilan;

- Liderstvo bazirano na osobinama lidera (Peters \& Waterman, 1982);

- Determinisanje liderstva kao transformacionog procesa (Burns, 1978); 


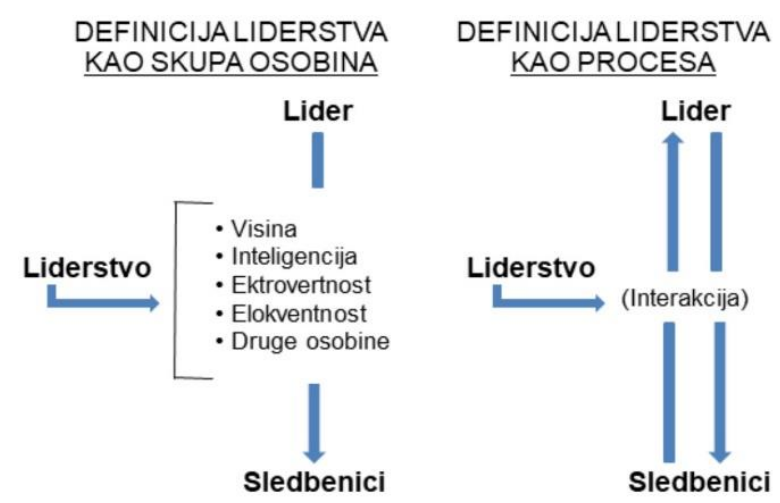

Slika 2. Različiti pogledi na liderstvo (Preuzeto i prilagođeno: Kotter, 1990)

Razlika između definisanja liderstva kao procesa i ponovnog posmatranja liderstva kroz osobine lidera može se videti na slici 2. Ako liderstvo povezujemo sa osobinama lidera, liderstvo će se definisati kao skup različitih svojstava koje pojedinci ispoljavaju u različitim merama, dok se, ukoliko mu se prisupa kao procesu, liderstvo konceptualizuje kao ponašanje lidera koje može biti naučeno (Jago, 1982).

\section{MODERNI PRISTUPI LIDERSTVU}

U 21. veku autori su počeli da pristupaju liderstvu na druge načine, a kojima je zajedničko da se liderom smatra pojedinac koji utiče na grupu pojedinaca da ostvare zajednički cilj (Northouse, 2016). Među ovim pristupima nalaze se:

1. Autentično liderstvo;

2. Spiritualno liderstvo;

3. Liderstvo služenjem;

4. Adaptivno liderstvo.

\subsection{Autentično liderstvo}

Jedna od teorija liderstva podrazumeva autentičnost lidera (Northouse, 2016). Među istraživačima ne postoji subliminirana definicija autentičnog liderstva, već se na ovom tipu liderstva pristupa sa različitih gledišta (Chan, 2005).

Autentični lideri ne samo da inspirišu i utiču na one sa kojima su u direktnom kontaktu, već ih i osnažuju da se pokrenu i sami vode. Ukoliko liderstvo posmatramo iz ovog ugla, može se postaviti nova definicija liderstva: Autentični lider okuplja ljude oko zajedničkog cilja i osnažuje in da se pokrenu i vode autentično u cilju stvaranja koristi za sve stejkholdere (George \& Sims 2007). Ovakav lider je jedinstven, iskren i radi ono u šta veruje, ima svoje mane i sklon je ljudskim slabostima i pravljenju grešaka. Ipak, prihvatajući svoje nedostatke i priznajući svoje greške lideri se povezuju sa sledbenicima i osnažuju ih. Autentični lideri iskazuju sledeće kvalitete: razumeju svoju ulogu, iskazuju jaka uverenja vrednosti, vode srcem, uspostavljaju povezane odnose i pokazuju samodisciplinu što je grafički prikazano na slici 3.

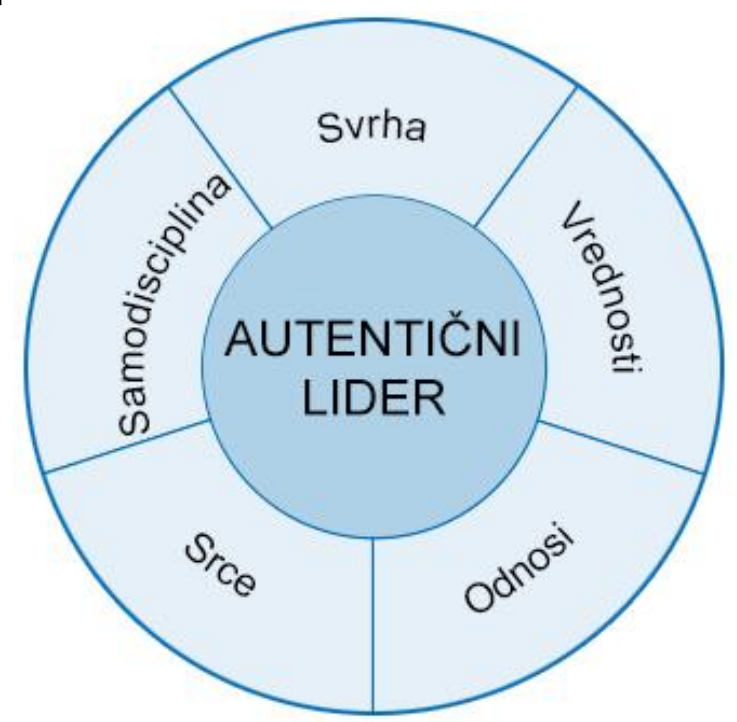

Slika 3. Dimenzije autentičnog liderstva (Preuzeto i prilagođeno: George, 2003)

Pojedini autori autentčino liderstvo opisuju kroz intrapersonalni pristup u kojem autentični lider ispoljava svoje liderstvo na iskren, originalan način radeći iz ubeđenja. Ovakav pristup podrazumeva da je svaki lider jedinstven na svoj način i ne predstavlja kopiju nekog drugog lidera (Shamir \& Eilam, 2005).

Drugi autori autentično liderstvo smatraju interpersonalnim procesom, u kojem se ono označava kao odnos koji lideri i sledbenici kreiraju zajedno (Eagly, 2005). Ukoliko se posmatra na ovaj način, autentično liderstvo predstavlja reciprocitetni proces $u$ kojem lider utiče na sledbenike i obratno i u skladu sa tim ne zavisi samo od lidera.

Autentično liderstvo se može posmatrati i kroz razvojnu perspektivu prema kojoj se ono posmatra kao nešto što može da se neguje u lideru više nego kao statična osobina (Avolio \& Gardner, 2005; Gardner, Avolio, Walumbwa, 2005; Walumbwa, Avolio, Gardner, Wernsing, Peterson, 2008). Prema ovom pristupu, autentično liderstvo se razvija tokom vremena pod uticajem dešavanja u životu lidera. 


\subsection{Spiritualno liderstvo}

Teorija spiritualnog liderstva se zasniva na viziji, altruističnoj ljubavi, veri i unutrašnjoj motivaciji (Fry, 2003). Spiritualno liderstvo se oslanja na fundamentalna uverenja i lidera i sledbenika $s$ jedne i osećaj pripadnosti s druge strane (Fleischman, 1994; Maddock \& Fulton, 1998). Pod fundamentalnim potrebama lidera $i$ sledbenika misli se na ona uverenja $u$ vezi sa osećajem da nečiji život ima značenje i da ostvaruje određeni uticaj i pravi razliku, dok se pod osećajem pripadnosti smatra lični osećaj da je pojedinac shvaćen, poštovan i prihvaćen bezuslovno.

Za razliku od ostalih modernih pristupa liderstvu svrha spiritualnog liderstva je da kreira viziju $i$ vrednosti koje su zajedničke i pojedincu i timu, ali i na nivou organizacije, negujući i unapređujući i posvećenost i produktivnost te organizacije. (Fry \& Whittington, 2005).

Spiritualni lider treba da stvori viziju gde članovi organizacije mogu da iskuse smislao onoga što $u$ njihovom životu ima smisla i šta to pravi razliku, kao i da uspostave društvenu ili organizacionu kulturu koncipiranu na altruističnoj ljubavi gde lideri i sledbenici brinu o istim problemima i gde cene i sebe i druge, imaju osećaj pripadnosti i osećaju se prihvaćenim i cenjenim.

\subsection{Liderstvo služenjem}

Pristup liderstvu koje posmatra ponašanje lidera i naglašava da vođenje računa o brigama $i$ problemima sledbenika od strane lidera naziva se liderstvo služenjem. U daljem tekstu ćemo in nazivati lideri sluge. Ovakav pristup liderstvu postoji u literaturi već četrdeset do pedeset godina (Greenleaf, 1970, 1972, 1977) iako mu se u poslednje vreme posvećuje više pažnje.

Lideri sluge brinu o problemima svojih sledbenika, ispoljavaju empatičnost i neguju ih. Ovi lideri na prvo mesto stavljaju svoje sledbenike koje osnažuju i pomažu im da dostignu svoj pun potencijal. Lideri sluge su etični i vode u pravcu koji služi višem cilju organizacije, zajednice ili društva uopšte (Northouse, 2016).

Ono što razlikuje lidere sluge od drugih lidera je to što stavljaju dobre osobine sledbenika iznad svojih ličnih interesa i na taj način podstiču sledbenike da se razvijaju (Hale \& Fields, 2007).
Svojim ponašanjem prema sledbenicima pokazuju jako izražena moralna načela (Walumbwa, Hartnell, \& Oke, 2010; Graham, 1991), a to isto čine i prema organizaciji i drugim stejkholderima (Ehrhart, 2004).

Postoje diskusije na temu da liderstvo služenjem treba da se posmatra kao osobina ili je ponašanje. $S$ obzirom na to da se ovaj pristup liderstvu vežba i može naučiti (Spears, 2010) liderstvo služenjem treba tretirati kao ponašanje.

\subsection{Adaptivno liderstvo}

Adaptivno liderstvo je jedan od novijih pogleda na liderstvo (Heifetz, 1994) koji za cilj ima da pruži odgovor na promene u okruženju. Ovaj pristup liderstvu bavi se razumevanjem i davanjem praktičnih načina i veza između liderstva, prilagođavanja (adaptacije), sistema i promene koji istovremeno ima duboke korene $u$ pokušajima naučnika da objasne evoluciju ljudskog života. Adaptivno liderstvo se definiše kao mogućnost lidera da mobiliše sledbenike da se suoče sa izazovima $i$ da $u$ tome uspeju i napreduju (Heifetz, Grashow, Linsky, 2009). Na ovaj način lideri sledbenike ohrabruju da se situacije adaptivnih izazova prepoznaju, da se prilagode i suoče sa nastalim problemima, ali in i pripremaju za situacije koje se nalaze van uobičajenih okvira i pomažu im da se sa njima suoče (Northouse, 2014).

Začetnici ovog pristupa govore o liderstvu kao praktikovanju mobilizacije ljudi da se suoče i izbore sa izazovnim promenama (Heifetz et al, 2009), dok adaptivni lideri sprovode aktivnosti koje mobilišu, motivišu, organizuju, orijentišu i usredsređuju pažnju na druge (Heifetz, 1994). Ovi lideri ohrabruju efektivnu promenu na različitim nivoima, od lidera, organizacije, zajednice i društva uopšte. Adaptivno liderstvo obuhvata ponašanje lidera $i$ aktivnosti koje oni preduzimaju da ohrabre druge da se suoče $i$ izbore sa promenama koje nastaju i koje sledbenici smatraju bitnim.

\section{ZAKLJUČAK}

Za svaku organizaciju je bitno da iskoristi pun potencijal ljudskih resursa na svim nivoima poslovanja. Negativno se na zaposlene odražava njihovo zapostavljanje što se dalje odražava i na njihove rezultate rada. Način funkcionisanja 
organizacija se godinama menja i prilagođava promenama različitih kontekstualnih faktora što dovodi $\mathrm{i}$ do promene pristupa liderstvu. $U$ početku, u centru liderstva bila je moć lidera $i$ izraženo naredbodavno ponašanje. Autori $i$ praktičari liderstva su osobine lidera smatrali izuzetno bitnim i samim tim su bile predmet izučavanja. Vremenom, odustajalo se od teorija u kojoj je lider rođen kao takav ili pojedinca liderom čine određene lične karakteristike, a u fokus su postepeno dolazili grupa i osobenosti sledbenika koji su činili grupu, njihova interesovanja, problemi, želje i uverenja. Uz manja odstupanja, moderne pristupe kompleksnosti liderskog procesa odlikuje upravo stavljanje grupe i odnosa lidera prema sledbenicima u fokus, dok se samo liderstvo najviše posmatra kao ponašanje koje može da se usavrši, a ne kao osobina ili lična karakteristika sa kojom je lider rođen.

Moderni lider ima želju i dovoljno kapaciteta da pre svega spozna sebe, razume koje su mu dobre, a koje loše strane i aktivno uči i radi na poboljšanju liderskih veština. Ovaj tip lidera poznaje sebe i upoznaje članove grupe, prepoznaje i bori se sa kontekstualnim faktorima, razume potrebe svojih sledbenika, vodi računa o njihovim interesovanjima, problemima, ulaže u njih i motiviše ih u cilju ostvarivanja što boljih poslovnih rezultata.

Savremeni pogled na liderstvo lidera posmatra kao pojedinca sa imenom i prezimenom, privatnim životom koji je ranjiv i dostupan za svoje članove grupe kojom rukovodi i koji i sledbenike posmatra na isti način.

\section{CITIRANI RADOVI}

Avolio, B. J., \& Gardner, W. L. (2005). "Authentic leadership development: Getting to the root of positive forms of leadership." Leadership Quarterly, 16, str. 315-338.

Bass, B. M. (1990). Bass and Stogdill's handbook of leadership: A survey of theory and research. New York: Free Press

Bass, B., \& Steidlmeier, P. (1999). Ethics, Character, and Authentic Transformational Leadership Behavior. Leadership Quarterly, 10(2): 181-217.

Bryman, A. (1992). Charisma and leadership in organizations. London: SAGE

Bryman, A., Collinson, D., Grint, K., Jackson, G., \& Uhl-Bien, M. (2011). The SAGE handbook of leadership. London: SAGE

Burns, J. M. (1978). Leadership. New York: Harper \& Row

Chan, A. (2005). Authentic leadership measurement and development: Challenges and suggestions. Oxford: Elsevier Science

Copeland, N. (1942). Psychology and the soldier. Harrisburg, PA: Military Service Publications

Day, D. V., \& Antonakis, J. (2012). The nature of leadership. Thousand Oaks, CA: SAGE

Drucker, P. (2017). What Makes an Effective Executive (Harvard Business Review Classics), Boston: Harvard Business Review Press

Eagly, A. H. (2005). "Achieving relational authenticity in leadership: Does gender matter?" Leadership Quarterly, 16, str. 459-474.

Ehrhart, M. G. (2004). "Leadership and procedural justice climate as antecedents of unit-level organizational citizenship behavior", Personnel Psychology, 57(1), 61-94.

Follet, M. P. (1924). Creative Experience. New York: Longmans, Green, and co.

Fry, L. W., \& Whittington, J. L. (2005). In search of authenticity: Spiritual leadership theory as a source for future theory, research, and practice on authentic leadership. Oxford: Elsevier

Gardner, J. W. (1990). On leadership. New York: Free Press

Gardner, W. L., Avolio, B. J., \& Walumbwa, F. O. (2005). Authentic leadership development: Emergent trends and future directions. Oxford: Elsevier Science 
George, B. (2003). Authentic Leadership: Rediscovering the Secrets to Creating Lasting Value, California: Jossey-Bass

George, B., \& Sims, P. (2007). True north: Discover your authentic leadership. San Francisco: JosseyBass

Heifetz, R. A. (1994). Leadership without easy answers. Cambridge, MA: Belknap Press

Heifetz, R. A., Grashow, A., \& Linsky, M. (2009). The practice of adaptive leadership: Tools and tactics for changing your organization and the world. Boston: Harvard Business School Press

Heller, T., \& Van Til, J. (1983). "Leadership and followership: Some summary propositions", Journal of Applied Behavioral Science, 18, str. 405-414.

Hemphill, J. K. (1949). Situational factors in leadership. Columbus: Ohio State University, Bureau of Educational Research

Hickman, G. R. (2009). Leading organizations: Perspectives for a new era. Thousand Oaks, CA: SAGE

Hollander, E. P. (1992). "Leadership, followership, self, and others", Leadership Quarterly, 3(1), str. 43-54.

Howell, J. M., \& Avolio, B. J. (1993). Transformational leadership, transactional leadership, locus of control, and support for innovation: Key predictors of consolidated business-unit performance. Journal of Applied Psychology, 78, 891-902.

Jago, A. G. (1982). "Leadership: Perspectives in theory and research“, Management Science, 28(3), str. 315-336.

Kotter, J. P. (1990). A Force for Change: How Leadership Differs From Management, New York: Free Press

Mayo, A., Nohria, N. (2005). "Zeitgeist Leadership“, Harvard Business Review, October

Moore, B. V. (1927). "The May conference on leadership“, Personnel Journal, 6, str. 124-128.

Mumford, M. D. (2006). Pathways to outstanding leadership: A comparative analysis of charismatic, ideological, and pragmatic leaders. Mahwah, NJ: Lawrence Erlbaum.

Northouse, P. (2016). Leadership - Theory and Practice. California: Sage

Northouse, P. (2014). Introduction to Leadership, California: Sage

Peters, T. J., \& Waterman, R. H. (1982). In search of excellence: Lessons from America's best-run companies. New York: Warner Books

Rost, J. C. (1991) Leadership for the Twenty-First Century, New York: Praeger

Sally, D. (2002) "Co-Leadership: Lessons from Republican Rome”, California Management Review, Volume 44, Number 4, str. 84-99.

Shackleton, V. (1995). Business Leadership. London: Routledge

Shamir, B., \& Eilam, G. (2005). "What's your story? A life-stories approach to authentic leadership development." Leadership Quarterly, 16, str. 395-417.

Stogdill, R. M. (1974). Handbook of leadership: A survey of theory and research. New York: Free Press

Tannenbaum, R., Schmidt, W. (1973). "How to Choose a Leadership Pattern“, Harvard Business Review, May-June

Walumbwa, F. O., Avolio, B. J., Gardner, W. L., Wernsing, T. S., \& Peterson, S. J. (2008). "Authentic leadership: Development and validation of a theory-based measure". Journal of Management, 34(1), str. 89-126. 
Datum prve prijave:

Datum prijema korigovanog članka:

Datum prihvatanja članka:
23.03.2018.

25.07.2018.

05.09.2018.

Kako citirati ovaj rad? / How to cite this article?

Style - APA Sixth Edition:

Mirčetić, V. (2018, 10 15). Razvoj liderstva i determinisanje modernog pristupa liderstvu. (Z. Čekerevac, Ur.) FBIM Transactions, 6(2), 90-97. doi:10.12709/fbim.06.06.02.10

Style - Chicago Sixteenth Edition:

Mirčetić, Vuk. 2018. „Razvoj liderstva i determinisanje modernog pristupa liderstvu.“ Urednik Zoran Čekerevac. FBIM Transactions (MESTE) 6 (2): 90-97. doi:10.12709/fbim.06.06.02.10.

Style - GOST Name Sort:

Mirčetić Vuk Razvoj liderstva i determinisanje modernog pristupa liderstvu [Časopis] // FBIM Transactions / ur. Čekerevac Zoran. - Beograd : MESTE, 1510 2018. - 2 : T. 6. - str. 90-97.

Style - Harvard Anglia:

Mirčetić, V., 2018. Razvoj liderstva i determinisanje modernog pristupa liderstvu. FBIM Transactions, 15 10, 6(2), pp. 90-97.

Style - ISO 690 Numerical Reference:

Razvoj liderstva i determinisanje modernog pristupa liderstvu. Mirčetić, Vuk. [ur.] Zoran Čekerevac. 2, Beograd : MESTE, 1510 2018, FBIM Transactions, T. 6, str. 90-97. 